\title{
Research Paper: The Effectiveness of Self-healing Training (Healing Codes) on Psychological Capital and a Sense of Cohesion in Drug Addicts
}

\author{
Zahra Irani $^{1}$ (D), Zohreh Latifi ${ }^{2 *}$ (D), Mohammad Soltanizadeh ${ }^{2}$ (D) \\ 1. Department of Counseling, Payam-e-Noor University, Iran. \\ 2. Department of Psychology, Payam-e-Noor University, Tehran, Iran.
}

$\begin{aligned} & \text { Use vour device to scan } \\ & \text { and read the article online }\end{aligned}$
Cftation Irani Z, Latifi Z, Soltanizadeh M. The Effectiveness of Self-healing Training (Healing Codes) on Psychological Capi-
tal and A Sense of Cohesion in Drug Addicts. Journal of Research \& Health. 2021; 11(5):351-362. http://dx.doi.org/10.32598/
JRH.11.5.1598.4

(c) (i) (3)

Article info:

Received: 13 Dec 2020

Accepted: 03 Apr 2021

Publish: 01 Oct 2021

\section{Keywords:}

Self-healing, Self-caring, Psychosocial intervention, Sense of cohesion, Addiction

\section{ABSTRACT}

Background: Drug addicts are exposed to many psychological and physical injuries due to the problems they experience in their lives; thus, they need training for psychological improvement. The purpose of this study was to evaluate the effectiveness of self-healing training on psychological capital and a sense of cohesion in drug addicts in 2020.

Methods: This study was a two-stage quasi-experimental study (experimental and control) in three stages (pre-test, post-test, and follow-up). Using convenience sampling, we selected 30 men willing to participate in the project and randomly divided them into the experimental $(n=15)$ and control $(n=15)$ groups. The Psychological Capital Questionnaire and the Sense of Coherence Questionnaire were administered as a pre-test. The experimental group underwent 14 sessions $(90$ minutes per week) of self-healing training. The follow-up was performed after 45 days. Analysis of the data involved both descriptive and inferential statistics, including mean, standard deviation, and the repeated measures ANOVA. Data analysis was done using SPSS version 24.

Results: The results showed that self-healing training had a significant effect on increasing psychological capital, increasing hope with the most effect and resilience with the least effect, as well as increasing participants' self-efficacy and sense of cohesion $(\mathrm{P}<0.05)$. The self-healing training had no effect on optimism. The results remained until the follow-up stage.

Conclusion: According to the results, self-healing training can be used as one of the new positive approaches to increase the mental health of drug addicts in treatment centers related to addiction with relatively lasting effects to increase self-care skills.

\footnotetext{
"Corresponding Author:

Zohreh Latifi, PhD.

Address: Department of Psychology, Payam-e-Noor University, Tehran, Iran

Phone: +98 (913) 1139781

E-mail: z yalatif@yahoo.com
} 


\section{Introduction}

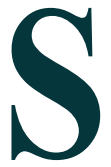

ubstance abuse and addiction have become one of the major concerns of human societies today. This home-burning phenomenon has devastating effects on the physical, psychological, occupational, financial, and moral aspects of life and has adverse effects on family and the society and also can lead to the loss of young human capital and thinking brains $[1,2]$. This destructive social phenomenon has penetrated many Iranian families and has caused deep and comprehensive disorders in the functioning of families [3]. Substance abuse not only causes pain and suffering to the user but also imposes a lot of burden and damage on the family and society $[4,5]$. Substance use disorder is defined as a set of cognitive, behavioral, and physiological signs indicating that a person is experiencing substance-related problems despite significant problems. Substance dependence is seen in all professions, educational levels, and socio-economic classes and is not only limited to a specific individual or group [6].

Addiction makes people addicted to drugs and exposed to high stress and reduces their resilience and psychological capital in the face of problems [7] and this process greatly reduces the likelihood of quitting drugs. Positive psychological capital includes self-efficacy, optimism, hope, and resilience, which indicates a person's positive assessment of the situation and the possibility of success based on effort and perseverance [8]. Studies show that optimism and positive thinking will lead to life expectancy and change of circumstances to create a positive mood and reduce the use of negative strategies, such as denying and giving up life responsibilities [9, 10]. Vanno et al. [11] reported that strengthening positive psychological capital, including selfefficacy, optimism, hope, and resilience, increases the ability to cope with difficult living conditions.

On the other hand, sensitivity to cohesion is another psychological factor influencing the tendency to use drugs and can play a dangerous or protective role against substance use. A sense of cohesion leads to the formation of beliefs that make the internal and external stimuli of the life path predictable and explicable. This personality trait makes a person use his resources and abilities to face a set of these stimuli and feel valuable [12]. Thus, people with high levels of this personality structure experience more positive psychological symptoms and are likely to have a healthier lifestyle [13]. In contrast, feelings of low cohesion are significantly associated with psychological problems, such as anxiety and depression $[14,15]$. Research has shown that therapies that increase the feeling of cohesion can be useful for managing stress and stress symptoms in people under treatment [5].
Self-healing is one of the new therapies of positive psychology that targets the management and control of physiological stress. This approach was formally introduced by Loyd (psychologist and complementary medicine therapist) and Johnson (cancer specialist) in 2011 in the United States under the heading of healing codes $[16,17]$. The self-healing approach includes memory retrieval skills, recognizing problematic personality traits, reducing harmful actions, teaching self-healing skills, praying, and practicing healing codes. Loyd believes that $95 \%$ of all physical and non-physical problems are caused by stress [18]. Situational stresses are stresses that have a specific source and are mostly external and recognizable, but physiological stresses are internal, overt, and covert stresses that are created and evoked by destructive cellular memories. Physiological stress causes the autonomic nervous system to become out of balance, in which there is no balance between state, war, and flight in the nervous system with normal state or relaxation. Loyd [19] believes that the cause of physiological stress in the body is "destructive cellular memory".

Destructive cellular memory is a memory that is stored in all cells of the body and reduces cellular energy and stress in the body. Loyd and Lipton [20] identify the causes of physiological stress as destructive cellular memories, negative emotions, unexplained fears, false images, and beliefs stored in the body and mind. These misconceptions in cellular memory cause people to mistakenly view their current situation as a threat, when in fact there is no threat, and this misinterpretation of the current situation triggers the unhealthy activation of the "war or "Escape" occurs in the brain. Persistent physiological stress can lead to mental disorders, and eventually a weakened immune system. Loyd believes that destructive cellular memories cause imbalance and aggravation of various mental disorders, such as resentment, narcissism, inability to control anger, irrational fears, depression, obsession, rejection and violence, low self-esteem, pessimism, idealism, disability in impulse control, procrastination, anxiety, detrimental actions, destructive communication, and reduced logical performance [21, 22].

The occurrence and increase of chronic physical disorders and the development of addiction and substance abuse, and the root of all the problems and destructive memories that people face in their lives, are related to one or more of the following reasons: resentment, harmful actions, misconceptions, and negative emotions, selfishness, sadness, anxiety, fear, anger, despair and intolerance (impatience), rejection and violence, feelings and inference are not good enough to control and create restrictions, unhealthy pride, arrogance, and deterrent 
image, and the loss of self-control [23]. The focus of this therapeutic approach is on the individual's efforts to treat destructive cellular memories, or cache memory, and to trace the root causes of physiological stress. In this treatment, spiritual excellence, having a healthy lifestyle, correcting internal conversations, correcting unhealthy fears and beliefs, meditating, praying, and performing exercises for healing codes is emphasized [24].

Based on psychological studies, according to the cultural, traditional, and religious principles of Iran, the executive protocol was prepared in 14 stages and approved by Latifi et al. [24]. This protocol has been scientifically and practically discussed in several meetings by a group of psychologists and counselors, and its effectiveness has been practically confirmed by several psychologists based on clients' reports. Accordingly, the present study was done to investigate the effectiveness of self-healing training (the healing codes) on psychological capital and a sense of cohesion in drug addicts.

\section{Methods}

This research was a quasi-experimental research with two groups (experimental and control) in three stages (pre-test, post-test, and follow-up). The statistical population of this study included addicted men who were referred to Isfahan addiction treatment centers in 2020. For implementation, after coordination with the provincial deputy of treatment and addiction treatment clinics in Isfahan, and obtaining the ethical code IR.PNU. REC.1398.157 from the National Committee of Ethics in Biomedical Research, invited addicts who had files in addiction treatment clinics who were willing to participate in the research, participated in the initial briefing session conducted by the researcher. Via convenience sampling, we selected 30 men and 15 participants were included in each group using the $G^{*}$ Power statistical software with an effect size of 1.8 , a test power of 0.90 , and $\alpha=0.05$.

The researcher carried out the randomization, and participants were allocated through selecting sealed opaque envelopes. Inclusion criteria were male gender, having a history of addiction for three years, the age range of 20 to 40 years, not receiving concomitant psychological treatment, having a minimum cycle degree, and completing the informed consent form. Exclusion criteria were having acute or chronic mental disorders (with the diagnosis of a clinical psychologist), taking medication, suffering from other physical illnesses, no cooperation during the training, not doing the homework presented in the sessions, and being absent for more than two sessions. After selecting the sample, the experimental group participat- ed in a 14-session self-healing training course (once a week for 90 minutes) at the addiction treatment clinic. For ethical considerations, the conscious willingness to participate in the research, ensuring the confidentiality of the subjects' information (the principle of confidentiality), and respect for the rights of the participants were considered. At the end of the study, to observe ethical considerations, the control group received an intensive course of self-healing training.

\section{Research instruments}

Luthans Psychological Capital Questionnaire: This questionnaire was designed in 2007 by Luthans. This questionnaire has 24 questions and includes four subscales of hope, resilience, optimism, and self-efficacy, in which each subscale contains 6 items and the subject answers each item on a 6-point Likert scale (strongly disagree to strongly agree). The validity of the questionnaire has been confirmed in various studies [25]. Using factor analysis and structural equations, Luthans [25] reported the Chi-square ratio of this test as 24.6 and CFI (Comparative fit index) and RMSEA (Root mean square error of approximation) statistics of this model as 0.97 and 0.08 , which confirmed the factor validity of the test. The reliability of the questionnaire in Iran has been reported by Bahadorikhosroshahi [26] based on Cronbach's alpha of 0.85 . In this study, Cronbach's alpha of the questionnaire was equal to 0.79 .

The Sense of Coherence Questionnaire: This is a 29item self-report tool whose questions are scored on a seven-point Likert scale from 1: rarely or never to 7: often. Therefore, the total score of this scale is in the range of 29 to 203, and a higher score indicates a higher level of sense of cohesion. In addition to the total score, this scale consists of three subscales that include perceptibility, controllability, and significance. Summarizing the results of 26 studies on the psychometric properties of the Cohesion Sense Scale shows that this scale has a high validity of Cronbach's alpha coefficients in the range of 0.82 to 0.95 [27]. Moeini et al. [5] reported the Cronbach's alpha of the questionnaire as 0.91 . In the present study, the reliability coefficient of this questionnaire was obtained 0.87 using Cronbach's alpha.

The control group was considered on the waiting list for post-test. After the training sessions, a post-test was performed for the experimental and control groups. Followup was further conducted for both groups after 45 days. A summary of the training sessions is provided in Table 1. 
Table 1. Self-healing session protocol [24]

\begin{tabular}{|c|c|}
\hline Sessions & Contents \\
\hline 1 & $\begin{array}{l}\text { Getting to know the group members and establishing a therapeutic relationship, defining the goals and rules of the ses- } \\
\text { sions, introducing situational stress and training in situational stress management, explaining the immune system, and the } \\
\text { role of stress on the functioning of the immune system. } \\
\text { Task 1: Examining situations and preparing a more complete list of worries, problems, and stresses by group members. }\end{array}$ \\
\hline 2 & $\begin{array}{l}\text { Explaining physiological stresses, latent stresses, or destructive cellular memories, and false memory. } \\
\text { Task 2: Observing yourself and evaluating the existing stress and performing relaxation of respiratory muscle at least once } \\
\text { a day (audio file of respiratory muscle relaxation as given). }\end{array}$ \\
\hline 3 & $\begin{array}{l}\text { Training to identify the real or false problem, training realistic and problem-oriented thinking, training to find memory } \\
\text { according to the failures, conflicts and failures and confusions of the person in life, conducting online memory testing test } \\
\text { (rose audio file assignment). } \\
\text { Task 3: Describing real and fictitious problems in your lives, starting reminiscence, the practice of meditation with the } \\
\text { audio file. }\end{array}$ \\
\hline 4 & $\begin{array}{l}\text { Rooting out destructive cellular memories, introducing three groups of resentment, misconceptions, and triangular nega- } \\
\text { tive emotions, harmful actions (audio file of memory retrieval was given to the members of the group). } \\
\text { Task 4: More detailed knowledge about resentment, examining the dimensions of secret beliefs, and cellular destructive } \\
\text { memories, retrieval with reminiscence file focusing on resentment group, finding related physical problems, taking medi- } \\
\text { cations, or relaxing your respiratory muscles. }\end{array}$ \\
\hline 5 & $\begin{array}{l}\text { Implementing the technique of glass elevator, remembering about traumas and very effective life events in all periods of } \\
\text { life, shocks, and Post-Traumatic Stress Disorder (PTSD) according to the individual's attitude, training and implementing } \\
\text { the technique of empty chair, discussing the harmful actions of group members, online memory analysis test at self- } \\
\text { healing. Performing temple meditation (temple meditation audio file was given to group members). } \\
\text { Task 5: Performing the empty chair technique at home with other destructive cellular memories and examining the } \\
\text { healthy or unhealthy feelings and beliefs that result from it, studying forgiveness and thinking about choosing forgive- } \\
\text { ness, reviewing your harmful actions, performing meditations, or relaxing your respiratory muscles at the discretion of } \\
\text { the group members. }\end{array}$ \\
\hline 6 & $\begin{array}{l}\text { Explaining the puzzle of positive and negative heart emotions and teaching forgiveness techniques, changing the focus of } \\
\text { group members from the past to the future, introducing nine unhealthy beliefs and negative emotions, introducing my } \\
\text { poor syndrome, teaching effective expression of emotions, teaching beautiful avoidance, analysis of harmful actions, and } \\
\text { performing light body scan meditation (audio file of body light scan was given to the group members). } \\
\text { Task 6: Continuing the mental challenge of reducing resentment and revenge, self-examination to recognize my poor } \\
\text { syndrome, examining unhealthy thoughts and believed lies, and recognizing problematic emotions (anger, lust, pride, } \\
\text { fear, sadness, and shame), and strengthening the willpower. Freedom, authority, and acceptance of responsibility for the } \\
\text { consequences of their behaviors, taking meditation, light scan of the body. }\end{array}$ \\
\hline
\end{tabular}

Treatment of harmful actions and bad and destructive habits by teaching methods of strengthening the will, four-factor program, problem-solving training and changing conditions and environment, training the technique of reverse memory.

$7 \quad$ Task 7: Investigating the role of my poor syndrome in destructive habits, recording successes and the skills used in the three restraint groups, performing the technique of reverse memory, performing meditations, or relaxing the respiratory muscles.

Strengthening the first to fourth healing codes, including love, happiness, peace, and patience. Selfish treatment training (lowering expectations, affection, fair behavior, and human attitude), understanding true happiness (paying attention to individual differences and increasing communication and enjoyable activities), relaxation training (self-training, time

8 management, correct relationship with mind, complete adjustment orientation (tolerance training (anger management, showing tolerance, and increasing resilience and hope).

Task 8: Starting a program to create and strengthen four healing codes in daily life,

identifying obstacles and recording successes and improvements, performing meditations, or relaxing the respiratory muscles.

Strengthening the fifth to ninth healing codes, including kindness, goodness, trust, humility, and self-control. Training to improve communication (with oneself, God, others, and nature), increasing the influence pressure (paying attention to the golden seal index, expressing the influence, and increasing self-confidence and self-efficacy), controlling treatment (reducing stubbornness and developing communication skills and positive thinking), treating unhealthy pride (taking care of oneself and others and spiritual empowerment), manual control treatment (increasing self-control, using response, and recognizing tomorrow's syndrome)

Task 9: Creating and strengthening nine healing codes in daily life, identifying obstacles, and recording successes and progress.

Explaining the role of real request, the effects of prayer, and the continued focus on desires in life and explaining the scientific evidence of prayer in self-healing, teaching creative visualization, teaching how to perform specific exercises of healing codes in a meeting (prayer audio file and audio file and how to perform specific exercises, and healing codes were provided).

Task 10: Spending some special time alone to pray and communicate with God and give thanks, (strengthen spirituality) exercises in silence and solitude and mental and physical awareness, clarifying your value system, performing creative visualization (positivity to the future). 


\begin{tabular}{|c|c|}
\hline Sessions & Contents \\
\hline 11 & $\begin{array}{l}\text { Balanced lifestyle training: Lifestyle modification by recognizing wrong habits and harmful actions, correcting sleep pat- } \\
\text { terns and adjusting food, how to eat, drink and have fun, travel, exercise, cleanliness, and hygiene. } \\
\text { Task 11: Practical implementation of healing code exercises along with prayer and preparation of true concentration sen- } \\
\text { tences, starting lifestyle modification by recognizing and reducing wrong habits. }\end{array}$ \\
\hline 12 & $\begin{array}{l}\text { Education to improve the quality of life in the areas of health, intimacy, and communication (parents, spouse, children, } \\
\text { relatives, and others), scientific growth, financial growth, career advancement, useful social activities, and home, neigh- } \\
\text { borhood, and community improvement. } \\
\text { Task 12: Continued practicing spiritual excellence, recognizing dissatisfaction in certain areas, and taking action to reduce } \\
\text { dissatisfaction. }\end{array}$ \\
\hline 13 & $\begin{array}{l}\text { Correction of internal dialogue, a re-examination of stress and strengthening breathing training, a re-examination of indi- } \\
\text { vidual stresses, emphasis on continuous self-care in the face of physical and psychological damage, and management of } \\
\text { emotions and communication. } \\
\text { Task 13: Continuation of previous exercises and correction of internal dialogue and self-care. }\end{array}$ \\
\hline 14 & $\begin{array}{l}\text { Teaching the techniques of spiritual excellence, trust, and surrender, explaining the triangular relationship, the spiritual } \\
\text { purpose of life, the need for introspection, and having } \\
\text { hours to be alone with oneself, planning for eternity. Overview of all treatment sessions and emphasis on continuing } \\
\text { healing code exercises. } \\
\text { Task 14: Continuing the previous exercises and recognizing the shortcuts of peace and spirituality for yourself }\end{array}$ \\
\hline
\end{tabular}

me:

In all sessions, while emphasizing confidentiality, all members of the group were asked to take part actively in the discussion and share their personal experiences with others, which should be performed using various techniques and tailored to each individual's taste. Participants were required to do the exercises individually in the session and in between sessions, and be sure to answer the instructor's reflection questions. Having privacy and thinking about yourself was an essential part of the exercise. Participants were asked to start training their family members or two friends at the same time in order to better understand the content and to raise the challenges in the meeting. In each session, the topics of the previous sessions were reviewed and homework was emphasized. The sessions were very interesting for the participants because the course was strongly related to their personal lives and the lives of others, and all participants reviewed their own life stories.

\section{Statistical analyses}

The repeated measures ANOVA was used to investigate the effectiveness of self-healing training on psychological capital and a sense of cohesion in drug addicts. SPSS Statistics version 24 was further used for analyzing the data.

\section{Results}

The sample size was 30 males with a mean age of 37.30 years with a standard deviation of 9.86 years in the experimental and control groups, respectively. Among the sample members, $30 \%$ had primary education, $40 \%$ had secondary education, $13.3 \%$ had a diploma, and $16.7 \%$ had a bachelor's degree. Among the sample members, $10 \%$ had no children, $20 \%$ had only one child, $43.3 \%$ had two children, $20 \%$ had three children, and $6.7 \%$ of the sample members had four children. Among drug addicts, $43.3 \%$ have been using drugs for under 10 years, $26.7 \%$ for 11 to 15 years, $16.7 \%$ for 16 to 20 years, and $13.3 \%$ for more than 20 years. The mean duration of addiction in drug addicts was 11.80 years with a standard deviation of 6.67 years. The mean and standard deviation of the pre-test, post-test, and follow-up scores of psychological capital scales and sense of cohesion are given separately for the two experimental and control groups in Table 2.

According to Table 2, the mean total score of the pretest of psychological capital and sense of cohesion in the experimental group was 79.42 and 61.14 , respectively, and for the control group was equal to 80.13 and 57.93 . Also, the mean total score in the post-test stage in the experimental group was 97.00 and 47.57 , respectively, and was 78.46 and 59.20 in the control group. In the follow-up, in the experimental group, it was reported to be equal to 98.00 and 46.57 , respectively, and in the control group, was 80.20 and 26.59 .

Assumptions of analysis of variance, including the normalization of pre-test and post-test distributions with Shapiro-Wilks test, complete lack of correlation between configuration variables, and homogeneity of variances with Levene's test were confirmed. The results of this test are shown in Table 3. As shown in Table 3 and considering the significance level of the scales, no value was less than 0.05 , and the null hypothesis of Levene's test based on homogeneity between the cohort and dependent groups was confirmed, and all these pairs of groups 
Table 2. Descriptive findings of psychological investment scale and sense of cohesion by experimental and control groups

\begin{tabular}{|c|c|c|c|}
\hline \multirow{2}{*}{ Scale } & \multirow{2}{*}{ Phases } & \multicolumn{2}{|c|}{ Mean $\pm S D$} \\
\hline & & Experimental Group & Control Group \\
\hline \multirow{3}{*}{ Self-efficacy } & Pre-test & $19.57 \pm 5.03$ & $17.00 \pm 5.64$ \\
\hline & Post-test & $25.00 \pm 3.06$ & $16.66 \pm 4.87$ \\
\hline & Follow up & $16.93 \pm 4.58$ & $25.78 \pm 3.33$ \\
\hline \multirow{3}{*}{ Hope } & Pre-test & $19.50 \pm 6.64$ & $20.60 \pm 8.72$ \\
\hline & Post-test & $25.21 \pm 3.32$ & $20.26 \pm 7.17$ \\
\hline & Follow up & $20.33 \pm 7.54$ & $25.64 \pm 3.24$ \\
\hline \multirow{3}{*}{ Resilience } & Pre-test & $19.42 \pm 4.41$ & $19.66 \pm 6.94$ \\
\hline & Post-test & $22.42 \pm 2.97$ & $19.13 \pm 6.49$ \\
\hline & Follow up & $23.00 \pm 3.30$ & $19.13 \pm 6.83$ \\
\hline \multirow{3}{*}{ Optimism } & Pre-test & $20.92 \pm 3.49$ & $22.86 \pm 5.02$ \\
\hline & Post-test & $24.35 \pm 1.90$ & $22.40 \pm 4.88$ \\
\hline & Follow up & $22.73 \pm 4.86$ & $23.57 \pm 2.27$ \\
\hline \multirow{3}{*}{ Feeling of cohesion } & Pre-test & $61.14 \pm 13.14$ & $57.93 \pm 16.85$ \\
\hline & Post-test & $47.57 \pm 7.75$ & $59.20 \pm 15.08$ \\
\hline & Follow up & $46.57 \pm 6.71$ & $59.26 \pm 15.26$ \\
\hline
\end{tabular}

IPHA

were homogeneous. As a result, another conditional assumption was provided for repeated measures ANOVA. Repeated measurement ANOVA was used to evaluate the effectiveness of self-healing training on psychological capital and sense of cohesion. One of the presuppositions of the statistical test is the repeated measurement of Mauchly's sphericity test. The results of this test are presented in Table 4.
Due to the insignificance of Mauchly's sphericity for psychological capital and sense of coherence, this hypothesis was confirmed $(\mathrm{P}<0.05)$. The values of Wilks's lambda test are given in Table 5.

According to Table 5 and values of $0.35,0.25$, and 0.19 for intergroup, intragroup, and interactive effects, respectively, self-healing training was effective on at least one of the scales of psychological capital and sense of cohesion. The results of intragroup and intragroup ANOVA

Table 3. Levene's test to examine the homogeneity of variance of cohort and dependent groups

\begin{tabular}{cccccc}
\hline Homogeneity of Co-scattering Group and Dependence of Scales & df1 & df2 & F & P \\
\hline Feeling of cohesion & 28 & 1 & 2.35 & 0.13 \\
Self-efficacy & 28 & 1 & 0.33 & 0.56 \\
Hope & 28 & 1 & 2.64 & 0.11 \\
Resilience & 28 & 1 & 3.43 & 0.08 \\
Optimism & 28 & 1 & 4.44 & 0.06 \\
\hline
\end{tabular}


Table 4. Mauchly's test for uniformity of covariance of self-healing intervention on psychological capital and sense of cohesion

\begin{tabular}{ccccc}
\hline Scale & Mauchly's Test & $\boldsymbol{\chi}^{2}$ & df & P \\
\hline Feeling of cohesion & 0.41 & 23.77 & 2 & 0.01 \\
Psychological capital & 0.35 & 27.65 & 2 & 0.01 \\
\hline
\end{tabular}

for the effect of self-healing training on psychological capital and sense of coherence with three measurements of pre-test, post-test, and follow-up are shown in Table 6.

According to Table 6 and the significance of the factors within the groups, the existence of a significant difference between the three measurements of pre-test, posttest, and follow-up for the dimensions of self-efficacy, hope, resilience, optimism, and sense of coherence was confirmed $(\mathrm{P}<0.01)$. Also, considering the significance of the group source among the groups, there was a significant difference between the experimental and the control groups for the dimensions of self-efficacy, hope, resilience, and sense of cohesion at the level of $\mathrm{P}<0.05$, but the group source was not significant for optimism. Therefore, self-healing training was effective on selfefficacy, hope, resilience, and sense of cohesion and was not effective on optimism.

\section{Discussion}

The present study tried to examine the effectiveness of self-healing training (the healing codes) on psychological capital and sensitivity to cohesion in drug addicts within the framework of a valid trial-based methodology. The results showed a significant difference between the three measurements of pre-test, post-test, and follow-up and the effectiveness of self-healing training on increasing psychological capital and sense of cohesion among participants. The results of this study showed that this intervention could significantly increase psychological capital in the dimensions of self-efficacy, resilience, and hope, and improve the sense of cohesion among participants.
According to the researcher's studies on the effect of the self-healing method on the psychological capital of drug addicts in Iran, only a few studies have been done so far, but similar research has been done in this field, including the results of Sadeghi and Karimi [28] in the field of improving the variables of psychological capital and about the feeling of cohesion. Also, Froehlich et al. [29] assessed the effect of self-healing on reducing alcohol use and improving anxiety and depression, and increasing quality of life as well as abuse of other drugs. Latifi et al. [24] evaluated self-compassion, concern about body image, and the process of recovery in patients with skin cancer. Zarean et al. [8] assessed psychological capital, enduring anxiety, and headaches of spouses of drug addicts. Latifi et al. [30] reported the improvement of hypertension, psychological well-being, and impatience in patients. Latifi et al. [31] assessed burnout, quality of life, and emotional resilience of social emergency personnel, based on the effect of self-healing training on psychological problems.

Regarding the effect of self-healing on increasing selfefficacy, it seems that people who are addicted to drugs gradually feel inefficient, helpless, and helpless after a period of inability to quit and their efforts to manage and improve their lives. Participating in self-healing sessions by emphasizing the ways to increase self-esteem, correcting bad habits and harmful actions, recognizing unnecessary fears, lies, and unhealthy thoughts, emphasizing the methods of strengthening the will (decision, care, evaluation, punishment, and reward), and teaching a balanced lifestyle and reflection to improve the quality of life in the areas of health, increased intimacy and communication (parents, spouse, children, relatives, and others) and useful social activities with an emphasis on

Table 5. Wilks's lambda test to examine the difference between the means of psychological capital and the sense of cohesion

\begin{tabular}{|c|c|c|c|c|c|c|}
\hline Sources & Statistical Power & $\eta_{p}^{2}$ & Sig. & df & $\mathbf{F}$ & $\mathbf{P}$ \\
\hline Between groups & 1.00 & 0.64 & 1.00 & 3 & 15.78 & 0.35 \\
\hline Intergroup & 1.00 & 0.75 & 1.00 & 6 & 11.49 & 0.25 \\
\hline Interaction effect & 1.00 & 0.80 & 1.00 & 6 & 16.23 & 0.19 \\
\hline
\end{tabular}


Table 6. The inter- and intra-participant analysis of variance with measurement

\begin{tabular}{|c|c|c|c|c|c|c|c|c|c|}
\hline Scales & $\begin{array}{l}\text { Within and Between } \\
\text { Subjects' Effects }\end{array}$ & Source & SS & df & MS & $\mathbf{F}$ & $\mathbf{p}$ & $\eta_{p}^{2}$ & $\begin{array}{c}\text { Statistical } \\
\text { Power }\end{array}$ \\
\hline \multirow{5}{*}{ Self-efficacy } & \multirow{3}{*}{ Within-subjects } & Phase & 157.35 & 1.57 & 100.21 & 27.84 & 0.01 & 0.49 & 1.00 \\
\hline & & Group $\times$ Phase & 177.08 & 1.57 & 112.78 & 31.33 & 0.01 & 0.52 & 1.00 \\
\hline & & Error & 158.22 & 43.96 & 3.59 & & & & \\
\hline & \multirow{2}{*}{ Between-subjects } & Group & 1026.84 & 1 & 1026.84 & 18.77 & 0.01 & 0.40 & 0.99 \\
\hline & & Error & 1531.11 & 28 & 54.68 & & & & \\
\hline \multirow{5}{*}{ Hope } & \multirow{3}{*}{ Within-subjects } & Phase & 163.26 & 1.25 & 129.92 & 17.72 & 0.01 & 0.38 & 0.99 \\
\hline & & Group $\times$ Phase & 198.86 & 1.25 & 158.25 & 21.59 & 0.01 & 0.43 & 0.99 \\
\hline & & Error & 257.86 & 35.18 & 7.32 & & & & \\
\hline & \multirow{2}{*}{ Between-subjects } & Group & 184.90 & 1 & 184.90 & 16.20 & 0.01 & 0.37 & 0.99 \\
\hline & & Error & 319.60 & 28 & 11.41 & & & & \\
\hline \multirow{5}{*}{ Resilience } & \multirow{3}{*}{ Within-subjects } & Phase & 42.75 & 2 & 21.37 & 14.80 & 0.01 & 0.34 & 0.99 \\
\hline & & Group $\times$ Phase & 79.02 & 2 & 39.51 & 27.35 & 0.01 & 0.49 & 1.00 \\
\hline & & Error & 80.88 & 56 & 1.44 & & & & \\
\hline & \multirow{2}{*}{ Between-subjects } & Group & 111.11 & 1 & 111.11 & 8.72 & 0.01 & 0.24 & 0.95 \\
\hline & & Error & 356.17 & 28 & 12.74 & & & & \\
\hline \multirow{5}{*}{ Optimism } & \multirow{3}{*}{ Within-subjects } & Phase & 38.42 & 1.24 & 30.95 & 7.99 & 0.01 & 0.22 & 0.94 \\
\hline & & Group $\times$ Phase & 60.95 & 1.24 & 49.10 & 12.67 & 0.01 & 0.31 & 0.96 \\
\hline & & Error & 134.62 & 34.76 & 3.87 & & & & \\
\hline & \multirow{2}{*}{ Between-subjects } & Group & 0.54 & 1 & 0.54 & 0.02 & 0.90 & 0.01 & 0.05 \\
\hline & & Error & 1168.57 & 28 & 41.73 & & & & \\
\hline \multirow{5}{*}{$\begin{array}{l}\text { Feeling of } \\
\text { cohesion }\end{array}$} & \multirow{3}{*}{ Within-subjects } & Phase & 898.15 & 1.26 & 711.96 & 39.30 & 0.01 & 0.58 & 1.00 \\
\hline & & Group $\times$ Phase & 1280.68 & 1.26 & 1015.19 & 56.04 & 0.01 & 0.66 & 1.00 \\
\hline & & Error & 639.82 & 35.32 & 18.11 & & & & \\
\hline & \multirow{2}{*}{ Between-subjects } & Group & 1973.51 & 1 & 1973.51 & 4.06 & 0.03 & 0.27 & 0.67 \\
\hline & & Error & 13584.31 & 28 & 485.15 & & & & \\
\hline
\end{tabular}

IPS:

continuous self-care against physical and mental injuries and emotion and communication management It probably caused the person to increase their sense of self-efficacy while establishing better communication and doing more useful activities. Concerning the strategies with a positive effect on increasing the resilience of addicts, humility and self-control can be mentioned because one of the important training in this course was to create and strengthen nine healing codes, including love, happiness, peace, patience, kindness, and trust. It seems that strengthening the healing codes and emphasizing the teaching of techniques of spiritual transcendence, deepening belief in God (an infinite power), trust and surrender (entrusting to God and letting go of troubles that one cannot solve) continuous prayer and supplication at least 
three times a day were effective in increasing resilience against hardships and problems.

On the one hand, considering that the feeling of cohesion is a general orientation and belief towards understandable, manageable, and meaningful life path events, and on the other hand, each person's beliefs and personality traits are among the factors that make him perform in stressful situations when a person develops beliefs that he or she can predict and understand what is going on in his or her life and that he or she can cope with what lies ahead, he or she feels valued. Thompson et al. [32] also reported that self-acceptance, self-friendliness, and sense of agency increased in depressed patients after training and correcting self-blame based on self-blame, inadequacy, and devaluation.

Regarding the reason for the effectiveness of selfhealing on increasing the sense of cohesion, emphasizing the spiritual purpose of life and increasing the inner richness (being useful and caring for oneself and others), introspection, explaining the creation of a triangular relationship instead of a linear relationship with self-esteem and planning for eternity, along with increasing communication with God, praying, and having a thoughtful solitude about values and the meaning of life were found to increase a sense of cohesion. Concerning the increase of the hope, it can be said that investigating the role of my poor syndrome in destructive habits, recording the successes and skills used in the three deterrent groups, practicing forgiveness, letting go of resentment, and recognizing the inner puzzle of positive and negative emotions, learning to manage situational stress were effective in improving this factor. Chopra and Tanzi [33] argued that it is necessary in the world where human beings at all times face many problems, such as chronic diseases, like high blood pressure and diabetes, problems and psychosocial pressures, such as possible epidemics to maintain existence, optimism, and psychological and social well-being, learn self-healing as a method of selfcare and use it over time so that as a habitual method, he or she can face the recurring challenges of today's world, especially for vulnerable people, such as addicts.

\section{Conclusion}

Self-healing training can be effective in improving psychological capital and a sense of cohesion in drug addicts. Therefore, the psychological problems in drug addicts can decrease by this training at different stages of treatment or after it. It is suggested to hold a self-healing training course in workshops of addiction treatment centers and consider this training in executive programs for consultants of uni- versities, especially rehabilitation centers to help solve physical and psychological problems in patients.

One of the limitations of this study is the gender of the sample members because all were male. It is suggested that in future research, other therapeutic approaches along with a self-healing therapeutic approach be used to compare and evaluate the effectiveness of different therapeutic approaches. Also, considering the emphasis of this approach on reducing physiological stress and increasing the immune system, as well as the prevalence of psychiatric diseases, it is suggested that in future research, the effectiveness of this method on other diseases with physical symptoms be investigated. It is also suggested that the training course of this intervention be used to train the required therapists in counseling and guidance centers in clinics or hospitals, and then, this treatment for drug addicts who have high levels of generalized anxiety and lack of emotional regulation.

\section{Ethical Considerations}

\section{Compliance with ethical guidelines}

This study was approved by the Ethics Committee of Payam-e-Noor, Tehran (Code: IR.PNU.REC.1398.157).

\section{Funding}

The paper was extracted from the MSc. thesis of the third author at the Department of Psychology, University of Payam-e-Noor.

\section{Authors' contributions}

Study design: Zahra Irani, Zohreh Latifi; Data collection and analysis: Zahra Irani; Manuscript preparation: All authors.

\section{Conflict of interest}

The authors declared no conflict of interest.

\section{References}

[1] Kamkar S, Farrokhi N, Salimi Bajestani H, Mardani Rad M. [Developing and testing of the causal model of students' addiction potential based on distress tolerance and differentiation with the mediating role of alexithymia (Persian)]. Etiadpajohi. 2020; 14(55):29-46. [DOI:10.29252/etiadpajohi.14.55.29]

[2] Askari P, Seyyed Asiaban S, Sangani A. [Comparison of the effect of tranquility and mindfulness on emotional cognitive regulation and family function in consuming slow-moving 
substances after poisoning (Persian)]. Etiadpajohi. 2020; 13(54):147-64. http:// etiadpajohi.ir/article-1-2017-en.html

[3] Saeidi F, Mohammadyfar MA. [Comparison of behavioral disorders between children with and without addicted parents (Persian)]. Etiadpajohi. 2018; 12(46):215-34. http://etiadpajohi.ir/article-1-1635-en.html

[4] Moshavery M, Latifi Z. ]Effectiveness of narrative therapy in generalized anxiety and stress coping skills among addicts wives under treatment in addiction treatment clinics (Persian)]. Etiadpajohi. 2019; 12(48):103-18. http://etiadpajohi.ir/ article-1-1685-en.html

[5] Moeini P, Malihialzackerini S, Asadi J, Khajevand Khoshly A. [The effectiveness of metacognitive training on sense of coherence and quality of life in spouses of addicted men (Persian)]. Etiadpajohi. 2020; 13(54):181-204. http://etiadpajohi. ir/article-1-2185-en.html

[6] Mostafaei $H$, Hosseini M, Jenaabadi $H$. The investigation of the relationship between the aggression and the addiction potential high school male students. J Manag Account Stud. 2014; 2(1):1-4. http://journals.researchub.org/index.php/ JMAS/article/view/43

[7] Molaei Yasavoli H, Abdi M. [The comparison of resiliency and coping strategies in individuals with drug addiction and normal (persian)]. Q J Soc Work. 2015; 4(1):24-9. http:/ / socialworkmag.ir/article-1-21-fa.html

[8] Zarean F, Latifi Z, Mirmahdi SR. [The effectiveness of selfhealing training on psychological capital, distress tolerance, and headache of addicts' spouses (Persian)]. Etiadpajohi. 2020; 14(55):193-212. [DOI:10.29252/etiadpajohi.14.55.193]

[9] Abbaspour Z, Karimi Vardanjani M, Khojastehmehr R. [The mediating role of fulfillment of marital expectations in the effect of marital satisfaction on high marital expectations, optimism and relationship self-efficacy in university personel (Persian)]. J Posit Psychol. 2019; 5(4):1-14. [DOI:10.22108/ PPLS.2020.116042.1684]

[10] Khaledian M, Mohammadifar MA. On the effectiveness of group cognitive-behavioral therapy and logotherapy in reducing depression and increasing life expectancy in drug addicts. Etiadpajohi. 2016; 9(36):63-80. http:/ / etiadpajohi.ir/ article-1-1109-en.html

[11] Vanno V, Kaemkate W, Wongwanich S. Effect of grouplevel positive psychological capital on group effectiveness of thai students. Procedia - Soc Behav Sci. 2015; 171:1309-14. [DOI:10.1016/j.sbspro.2015.01.246]

[12] Arghabaei M, Soleimanian AA, Mohammadipour M. The Role of Family Emotional Atmosphere, Sense of Coher- ence, and Affects in the Prediction of Tendency Toward Substance Use Among University Students. Iran J Psychiatry Clin Psychol. 2018; 24(3):310-23. [DOI:10.32598/ijpcp.24.3.310]

[13] Kikuchi Y, Nakaya M, Ikeda M, Okuzumi S, Takeda M, Nishi M. Sense of coherence and personality traits related to depressive state. Psychiatry J. 2014; 2014:738923. [DOI:10.1155/2014/738923] [PMID] [PMCID]

[14] Grevenstein D, Bluemke M, Nagy E, Wippermann CEM, Kroeninger-Jungaberle $\mathrm{H}$. Sense of coherence and substance use: Ex- amining mutual influences. Personal Individ Dif. 2014; 64:52-7. [DOI:10.1016/j.paid.2014.02.017]
[15] Tóth A, Soós R, Szovák E, Najbauer NM, Tényi D, Csábí G et al. Energy drink consumption, depression, and salutogenic sense of coherence among adolescents and young adults. Int J Environ Res Public Health. 2020; 17(4):1290. [DOI:10.3390/ijerph17041290] [PMID] [PMCID]

[16] Soltani M, Latifi Z, Moosavi SR. [The effect of self-healing education on self-compassion, body image concern and improvement of disease process in suffering from skin cancers (Persian)] J Dermatol Cosmet. 2020; 10(4):222-34. http://jdc.tums.ac.ir/ article-1-5417-en.html

[17] Loyd A. The Relationship Codes; Alexander Loyd Services, LLC, 2430; 2014. https://www.dralexanderloyd.com/the-relationship-codes/

[18] Loyd A. The Healing Codes will revolutionize heal. MANUAL Alex Loyd Services, LLC, 2013. https://www.dralexanderloyd.com/the-relationship-codes/

[19] Loyd A. The Healing Codes II; A step-by-step guide to wholelife healing; Publisher: Yellow Kite, 2019. https:/ / www.dralexanderloyd.com/the-relationship-codes/

[20] Loyd A, Lipton BH. The biology of belief: Unleashing the power of consciousness, matter \& miracles. Carlsbad: Hay House; 2016. https:// books.google.com/books?id=Q2H6DwAAQBAJ\&dq

[21] Loyd A. The Memory Engineering; Alexander Loyd Services, LLC, 2018. publisher. Hodder \& Stoughton. https:/ / www.dralexanderloyd.com/the-relationship-codes/

[22] Loyd A. The healing codes: Unlocking the cellular sequence of life. New York: Light of Man Ministries; 2006. https:/ / books. google.com/books?id=TNPOvQEACAAJ\&dq

[23] Loyd A, Johnson B. The healing codes. Grand central life \& style. Hachette book group. New York. Boston, First book edition: February 2011. https://www.grandcentralpublishing.com/titles/alexander-loyd-phd-nd/the-healing-code/9781611138351/

[24] Latifi Z, Soltani M, Mousavi S. Evaluation of the effectiveness of self-healing training on self-compassion, body image concern, and recovery process in patients with skin cancer. Complement Ther Clin Pract. 2020; 40:101180. [DOI:10.1016/j. ctcp.2020.101180] [PMID]

[25] Luthans F, Youssef CM, Avolio BJ. Psychological capital: Investing and developing positive organizational behavior. Posit Organ Behav. 2007; 1(2):9-24. [DOI:10.4135/9781446212752.n2]

[26] Bahadori Khosroshahi J, Hashemi Nosratabad T, Babapur Kheyroddin J. [The relationship between social capital and psychological well-being among the Students of Tabriz University (Persian)]. Soc Cogn. 2015; 3(2):44-54. http://sc.journals.pnu. ac.ir/article_1360.html?lang=en

[27] Antonovsky A. Unraveling the mystery of health. How people manage stress and stay well. San Francisco: Wiley; 1987. https:// books.google.com/books?id=6HVHAAAAMAAJ\&q

[28] Sadeghi M, Karimi F. [The effectiveness of psychological cognitive capital intervention on cognitive flexibility and resilience of addicted people (Persian)]. Etiadpajohi. 2018; 12(48):83-102. http://etiadpajohi.ir/article-1-1214-en.html

[29] Froehlich J, Nicholson E, Dilley J. Dual therapy for alcohol use disorders: Combining naltrexone with other medications. In: Preedy VR, editor. Neuroscience of Alcohol. Cambridge: Academic Press; 2019. pp. 653-660. [DOI:10.1016/B978-0-12-8131251.00067-2] 
[30] Latifi Z, Gharaghani R, Mardani Z. The effectiveness of self-healing training on lifestyle and symptom management in women with hypertension. hrjbaq. 2020; 6(1):77-66. http:/ / hrjbaq.ir/article-1-457-en.html

[31] Latifi Z, Shafie L, Soltanizadeh M. [The effectiveness of selfhealing training on job burnout, quality of life, and emotional flexibility in Isfahan's social emergency personnel (Persian)]. Ebnesina. 2021; 23(2):36-47. http://ebnesina.ajaums.ac.ir/ article-1-972-fa.html

[32] Thompson K, D'iuso D, Schwartzman KS, Drapeau M. Changes in depressed patients' self-statements. Psychother Res. 2020; 30(2):182-70. [DOI:10.1080/10503307.2018.1543976] [PMID]

[33] Chopra D, Tanzi RE. The healing self: A revolutionary new plan to supercharge your immunity and stay well for life. New York: Harmony Books; 2018. https:/ / books.google. com/books?id=QwtFDwAAQBAJ\&dq 
This Page Intentionally Left Blank 